International Journal of Linguistics, Literature and Translation (IJLLT)

ISSN: 2617-0299 (Online); ISSN: 2708-0099 (Print)

DOI: $10.32996 / \mathrm{ijllt}$

Website: https://al-kindipublisher.com/index.php/ijllt

IJLLT

\title{
English and Japanese Inner Aspect
}

Ploscaru Mihaela-Alina

PhD. Candidate at Babeș-Bolyai Universiy, Romania

Ploscaru Mihaela-Alina, E-mail: ploscarualina@yahoo.com

\section{ARTICLE INFORMATION}

Received: September 15, 2020

Accepted: October 26, 2020

Volume: 3

Issue: 10

DOI: $10.32996 /$ ijllt.2020.3.10.14

\section{KEYWORDS}

Inner Aspect, verb, syntax, semantics, English, Japanese, semantic operators

\section{ABSTRACT}

The aim of the current paper is to revisit the topic of Inner Aspect, and explore it from two vantage points, taking both English and Japanese data into account. We will rely on Vendler's classification of verbs, and use it so as to see whether the verb classes he introduced for English can also account for Japanese verbs. To do this, we will make use of a number of tests that Vendler as well as other authors have suggested. We will see that not all verbs can pass these tests, and that sometimes, in order for a verb to pass them, we have to entertain specific scenarios to allow them to do so. Lastly, we will turn our attention to the Japanese morpheme -te iru (the counterpart of the English -ing) and explore a specific interpretation that this morpheme allows in Japanese, interpretation which cannot be found in English: the state-result interpretation. The paper concludes with the argument that because the state-result reading is not available in English, then -ing morphology is appears to not be compatible with two verb classes: activities and achievements.

\section{Introduction}

Although Aspect has been discussed in relation to a number of languages, the research usually focused on the progressive reading, which signals that an action is or was taking place at the moment of speech. However, as we will shortly see, this reading is not the only one available when dealing with this topic, and we must turn our attention to the state-result interpretation that can be borne out when a verb is conjugated using imperfective morphology. In order to explain why English does not allow this second interpretation, we have to look at another language, where state-result readings are available. This will be done by comparing Japanese data with the English one, and by corroborating the results so as to see what they have in common, and how they are differ. Moreover, the paper makes use of both semantics and syntax to account for the two interpretations. We chose this method as we support the idea that semantics and syntax work together to bring about the two interpretations. Unlike previous research, our paper is a comparative study of the same phenomenon, and it acts as a starting point for further research related to the state-result interpretation both in Japanese, and in English. We refer to English as well because as it might be that this interpretation can be found with English verbs, although we could not discuss this possibility here.

\section{Literature Review}

Outer Aspect, the one which we are usually most familiar with, is concerned with the way in which a speaker relates to a situation that he/she describes. This simple definition allows us to differentiate Aspect from Tense simply because one does not need to take into account the time of speech in order to use a verb in a certain aspect. We can think of this distinction in Comrie's terms $(1976$, p. 3) "aspects are different ways of viewing the internal temporal constituency of a situation". There are a number of languages which make a distinction between Aspect and Tense, and the difference can be seen in the example below, where we take French into consideration:

1. Elize dormait quand il lui ai téléphoné.

Elize sleep.IMP when he her have.PAST telephone.PAST.PART

'Elize was sleeping when he phoned her'.

K C AL-KINDI CENTER \begin{tabular}{lll}
$\mathbf{R}$ & D FOR RESEARCH AND \\
\hline
\end{tabular}

Your gateway to world-class research
Published by Al-KindiCenter for Research and Development. Copyright (c) the author(s). This is an open access article under CC BY license (https://creativecommons.org/licenses/by/4.0/) 
We see that both sentences have a first part which is used offer the background information for the action that takes place in the second part. The background, however, is an event that was still going when the phone rang. To refer to this background the term imperfective is used. The verb phoned, however, is in the perfective aspect, as the action is seen as completed. We also see that both verbs are accompanied by morphological items (was + ing and -ed) which help us identify each of the two interpretations.

However, for Inner Aspect, morphological items are not needed in order to interpret the way in which a situation is described. According to Comrie (1976), there are three features that need to be taken into account to interpret a situation: durativity, dynamicity, and telicity. If the verbs lack these features, then they are classified as punctual, stative and atelic. Durative verbs stretch in time, either indefinitely, or for a fixed period. An example of such verbs is the verb dance ${ }^{2}$, which unlike a verb like blink, needs more than a couple of moments to come about. Dynamic verbs require movement in order to be realized. Such verbs are play, sing, or cook, while punctual verbs express a situation that persists without needing a constant effort to support it. Such situations are expressed by verbs like know, love, or hate. Finally, Comrie talks about telic verbs to describe those verbs which have inherent endpoints encoded in their semantic interpretation. More specifically, a verb phrase like play a game is considered to have an intrinsic endpoint signalled by the actual ending of the game, while a verb like play taken alone cannot measure out the event in the absence of the direct object. Because they can go on indefinitely, verbs like play, dance, or paint are referred to using the term atelic.

However, Comrie's classification of the internal features of the verbs was proposed only after Vendler published his 1967 essay, entitled Verbs and Times. This essay is viewed as the starting point of research related to Inner Aspect, as Vendler points out that the most important test we can use to distinguish between verbs of different types is to actually make use of the Outer Aspect morphology (-ing), and thus account for the Inner Aspect of English verbs. Later, this test was used to account for other languages as well, and we will also make use of it to talk about Japanese verbs. In Vendler's view, we can use the -ing imperfective morphology to test whether verbs accept this morpheme, or if they reject it. Based on this, he classifies verbs into: states, activities, accomplishments, and achievements. Among these classes, only two can function with the imperfective, and these are activities and accomplishments. Vendler's ideas were, however, questioned by other authors (Comrie 1976, MacDonald 2008 and 2009, Travis 2010 etc.), who have argued that speakers can, and actually do use stative and achievement verbs in the imperfective. However, in order for this to happen, a verb would have to have its meaning coerced, and this is not the case with Vendler's examples, which do not need the speaker and interlocutor to entertain a scenario that would allow for the imperfective reading. An example of an achievement being used with -ing morphology is Comrie's (1976: 42) "he was coughing." However, he makes sure to point out that in this case, the verb is not seen as being in the progressive (the aspect which Vendler was interested in), and that a sentence containing these words would imply that "the reference is to a series of coughs" (Comrie, 1976, p. 42).

However, should we corroborate Vendler and Comrie's findings, then it would follow that the four types of verbs would have to following characteristics:

1. States [-dynamic, +durative, +atelic]

2. Activities [+dynamic, +durative, +atelic]

3. Accomplishments [+dynamic, +durative, +telic]

4. Achievements [-durative, +dynamic, +telic]

Other authors have talked about Inner Aspect in terms of the sematic operators that are associated with the four types of verbs. Rappaport Hovav and Levin (1998) propose that the semantic representation of verbs makes use of three semantic operators to account for the interpretation that verbs receive. These operators are CAUSE, ACT, BECOME, and STATE. The "event structure template" (Rappaport Hovav \& Levin, 1998, p. 108) that they propose are listed below:

$\begin{array}{ll}{[\mathrm{x} \text { ACT }<M A N N E R>]} & \text { (activity) } \\ {[\mathrm{x}<\text { STATE }>]} & \text { (state) } \\ {[\mathrm{BECOME}[\mathrm{x}<S T A T E>]} & \text { (achievement) } \\ {[[\mathrm{x} \text { ACT }<M A N N E R>\text { CAUSE }[\mathrm{BECOME}[\mathrm{y}<\text { STATE }>]]]} & \text { (accomplishment) } \\ {[\mathrm{x} \text { CAUSE BECOME }[\mathrm{y}[<S T A T E>]]} & \text { (accomplishment) }\end{array}$

\footnotetext{
${ }^{2}$ This verb is also classified as a semelfactive, however, we do not deal with them in this paper.

${ }^{3}$ Here, the verb would no longer be classified as an achievement, but it would be used as an iterative, i.e. as a verb that signals a repetitive action.
} 
The two authors also account for the multiple meanings that verbs receive arguing that "multiple meanings usually arise from the association of a single constant with more than one semantic template" (Rapport Hovav \& Levin, 1998, p. 107). The semantic template is the series of possibilities that a language allows for a verb to be part of, and the constants are the usually modifiers or arguments of predicates.

Similarly, Uesaka (1996, p. 80) uses the aspectual predicate BE to refer to the semantic representation of state and activity verbs. Thus, she employs $\mathbf{A C T}$ as well as $\mathbf{B E}$, and we argue that this process bears out the following representation in the case of states: [BE $\mathrm{x}\langle S T A T E>]$. For activities, however, the combined structure is more complicated, as Rappaport Hovav and Levin (1998) do not associate BE with activities ${ }^{4}$, but only with accomplishments. However, Uesaka differentiates between them in terms of whether BE or BECOME can appear under Asp in the syntactic tree of such verbs. Thus, the collapsed structure that we propose would be the following:

$$
\text { [ } x \text { ACT <MANNER> }] \text { CAUSE }[x \text { BE }(y---z)] \text {, }
$$

where $\mathbf{B E}(\mathrm{y}---\mathrm{z})$ is a temporary state which exists provided that the activity does not cease.

In the following part of the paper, we will analyse a number of sentences from both English and Japanese, and we will try to see whether these sentences can be used with imperfective morphology to signal on-going situations, and if their syntactic trees reflect their semantic patterns as well.

\section{Methodology}

The main instrument that we will use in order to explore the imperfective and state-result interpretations consists of a number of tests that have been discussed in the literature so as to account for the readings that the four classes of verbs receive. These tests have been proposed mainly by English authors, however, a number of them have been used by Japanese researchers as well. Other tests, like the It took $x$ time construction, and the test which focuses on the adverb almost have been proposed by us in order to account for Japanese data. These tests will be further divided into two: stative-non-stative tests, which distinguish verbs based on all of their internal aspectual features. They are also referred to as preliminary tests. However, after applying these tests, we will see that an issue arises: two classes of verbs appear to behave in the same way. Because of this, we will turn our attention to a second set of tests, based on the telic-atelic natures of the four verbal classes. As the nature of this study is theoretical, we will apply the tests to a number of example sentences taken from both languages, and see which of them can construct sentences that are correct from a grammatical point of view, and which of them do not. Afterwards, we will design syntactic trees in order to explain how the two interpretations come about at the level of syntax, and we will compare these trees so as to shed light on why only certain verbs pass the tests mentioned above.

\section{Results and Discussion}

Based on the work done by the authors we have discussed so far in this paper, we will now endeavour to analyse a number of sentences with the aim of seeing whether the four verbal classes proposed by Vendler can be conjugated in the imperfective, both in English and in Japanese. Before we proceed, we must mention that Japanese uses the -te iru/itta morphemes to signal the imperfective. Iru and itta are the verb 'to be' conjugated for present and past, and they correspond to the 'to be' auxiliary in the English imperfective constructions: is -ing or was -ing. For clarity purposes, we will first account for the English data, and then for the Japanese example sentences. It is, however, important to mention that the literature makes use of two types of tests to account for Inner Aspect. These tests are the stative-non-stative tests, and the telic-atelic tests. Let us start with the first type of tests, which, according to Dowty (1979, p. 55), is further divided in four tests: a) the progressive (based on Vendler's findings), b) imperative forms, c) agentive adverbs, and d) whether the verbs can appear as the complement of force and persuade.

\subsection{Stative-non-stative tests (English)}

The first type of verbs considered to be incompatible with imperfective morphology are states. This view is supported by the fact that a state extends indefinitely in time after it has begun/been instituted. If the imperfective tells us that an event is/was going on at a certain moment, then states cannot be compatible with this exact moment. Hence why the sentence below is not acceptable in Vendler's definition.

1. a. *Mary is being worried about the test.

\footnotetext{
${ }^{4}$ Uesaka (1996) argues that CAUSE is present in the semantic interpretation of activity verbs.
} 
Moreover, stative verbs are a class of verbs that fails the other tests which Dowty (1979) proposes. We cannot use them to construct grammatical imperative sentences, and we cannot modify the verbs with agentive adverbs like deliberately, intentionally or carefully. The examples below can be regarded as evidence for these claims:

b. *Love your fiancé right away!

c. *George deliberately/carefully loves video games.

d. *Alice persuaded/forced Christina to love spinach.

Unlike states, activities pass all the tests mentioned above, and this can be seen from the examples in 2 below.

2. a. Martha was running in yesterday's marathon.

b. Run carefully, Martha!

c. Martha intentionally ran past the coffee shop that morning.

d. Mrs. Simian persuaded Martha to run in the marathon.

Farkas (2017, p. 147) points out that the reason activities can occur with the progressive without having to coerce the meaning of the verb has to do with the fact that activities are regarded as events that unfold in time, consisting of "successive phases following one another in time" (Vendler, 1967, p. 144), while states consist of a single phase that stretches indefinitely in time.

The second class of verbs which passes all four of the stative-non-stative tests is the class of accomplishments. Sentences (4a4d) illustrate this:

3. a. Martha is eating a mango.

b. Eat that mango already!

c. Martha deliberately ate the last mango on the table.

d. George persuaded Martha to eat the last mango.

We see that accomplishments and activities pass all the tests. However, they are still considered to be two distinct classes. This is because accomplishments need a direct object to measure out the event of the verb. Thus, they are only similar to activities. There are, however, authors who group these verbs under only one class ${ }^{5}$, but we will not touch upon this aspect in the present paper.

Vendler's achievements also fail the preliminary tests because, like states, they cannot be used with progressive morphology. This is due to their punctual or near-instantaneous nature. As they lack duration, they are incompatible with -ing, and they do not take agentive adverbs because of their theta-role grid $^{6}$. Nor can they appear with force/persuade provided that we do not entertain a specific scenario that would allow for the insertion of these words.

4. a. *Martha is noticing the vintage furniture.

b. ?Arrive at the gate!

c. *Martha carefully/deliberately won the drawing contest.

d. $*$ George forced Martha to spot the difference between the two texts.

\subsection{Telic-atelic tests (English)}

The second test deals with the telic-atelic distinction. This test, is in turn divided into four tests: a) the in/for time adverbial test b) the It took $x$ time test, $\mathbf{c}$ ) the complement of stop/finish, and d) the compatibility with the adverb almost.

The in/for-time adverbial test is proposed by Dowty $(1979, \mathrm{p} .56)$ to draw the distinction between activities and accomplishments. However, we will apply this test to the remaining two verb classes, as one can see below:

5. a. Martha hated strawberries for/*in months.

b. Dan danced for/*in two hours.

c. Leah ate the mango in/*for ten minutes.

d. The kid broke the vase in/*for one second.

\footnotetext{
${ }^{5}$ See Comrie (1976) for the classification of verbs into states, events, and processes.

${ }^{6}$ Achievements are compatible with the Experiencer theta-role, and this theta-role is incompatible with agentive constructions.
} 
However, there have been authors who have argued that sentences like those in (5b) and (5c) above can receive an interpretation even when they are used with for. Verkyul (1989) argues that the in-time adverbial can elicit a second interpretation when combined with activities and accomplishments. His proposes the following: unlike for, in "can have the meaning of "it took him (less than)" (Verkyul, 1989, p. 50) two hours to dance/to eat the mango. Moreover, Farkas (2017, p. 160) agrees that "with the for-time adverbial, the emphasis is only on the process/activity" that the verb denotes, while "with the in-time adverbial, the emphasis is on the endpoint of the process/activity." This distinction is related to the telic-atelic nature of the two verb classes. Hence, even though accomplishments are telic in sentences where there is no time adverbial, they can sometimes receive an atelic interpretation, and vice-versa in the case of activities.

The second telic-atelic test was introduced by Vendler (1967), as he pointed out that only certain verbs can appear in a construction like 'It took $x$ time for someone to start an event'. Now let us see which verbs are compatible with this construction.

6. a. ${ }^{*}$ It took Martha two months to like strawberries.

b. It took Christina ten minutes to sing in front of the crowd.

c. It took my friend one hour to eat the whole pie.

d. It took mom three minutes to find her car keys.

If we rely on what Vendler proposes, then it would follow that achievements should not be compatible with this test, as due to their near-instantaneous nature, it would be difficult to entertain that one actually finds their keys in three minutes. Here, more clarification is needed: we can look for the keys for three minutes, but it only takes one split second to actually spot them somewhere around the room. To explain why sentence (6d) still constitutes proper English, we will have to take a look at what MacDonald (2008) proposes: the It took $x$ time construction can have two readings, according to the type of verb it combines with. The readings are "a start-time and an end-time" (MacDonald, 2008, p. 68) meanings, and they correspond to telic, and respectively atelic verbs. This explains why achievements can appear with this construction: the focus is on the endtime of the process of finding, and this process ends only when the actual finding of the keys takes place. If we were to focus on the event of finding the keys, then the sentence would not be acceptable.

In the same way, we can explain why activities and accomplishments can receive both interpretations: one group is atelic (activities), and the other one presupposes an endpoint, that is to say, falls in the telic sphere (accomplishments). Because the It took $x$ time test allows us to focus on one part of the whole event described by the verb, it makes sense that we can shift this focus so that atelic verbs become telic, and vice-versa. Their dynamic nature also plays a part in this.

The last test deals with the Vendlerian verbs' ability to function in a sentence together with the adverb almost. MacDonald (2008) argues that this adverb can also elicit two different interpretations, a case which is similar to the test discussed above. In his terms, the two interpretations are "a counterfactual and an incompletive interpretation" (2008, p. 65). The sentences below show these interpretations.

7. a. *Mike almost loved Suzy.

b. Christina almost swam in the lake.

c. Martha almost ate the pudding.

d. The dog almost bit the kid.

States (as they either occur, or do not) cannot form proper sentences when used with almost. Achievements (7d), due to their telic nature, can elicit a counterfactual interpretation, and not an incompletive one because this would contradict their instantaneous nature. As activities are atelic, they can only receive a counterfactual interpretation, and almost can only modify the initial point of the event. Accomplishments, on the other hand, have a two-fold nature: they consist of a process which we can also identify in the case of activity verbs. On the other hand, they receive their telic interpretation because their internal argument is undergoing a specific change: in the case of eat the pudding, the change is reached when the last bit of pudding is fully consumed. Hence, an accomplishment like the one in (7c) can be read as having both a counterfactual interpretation (where Martha was about to eat a spoonful of pudding, but ultimately, she did not), and an incompletive interpretation (where Martha started eating the pudding, but could not finish all of it).

Now let us turn our attention to Japanese verbs, which we will classify using the same terminology, at least for the moment. 


\subsection{Stative-non-stative tests (Japanese)}

In the same way that we dealt with English verbs, we will first examine sentences built on the first set of tests, i.e. the stativenon-stative tests, the first of which ${ }^{7}$ is signalled by the -te iru morpheme cluster.
8. a. Kare-wa chiisai oto ni made
obie-te iru
ne.
He.TOP faint sounds PART even
be afraid of.PROG.PRES PART

'He is afraid even of faint sounds.'

Smith's (1991: 3) definition of the imperfective helps us understand why Japanese states can occur with imperfective morphology. Remember from the beginning of the paper that the imperfective signals that the speaker chooses to focus only on one part of a certain event, i.e. the part that is still going on. However, the perfective encompasses all the stages of the event: initial, middle and final point. Shirai (1998b) proposes that the middle part of a verb used in the imperfective can, in turn, be divided into three parts, as shown by his diagram:

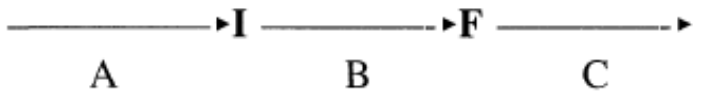

"When the imperfective focuses on Phase A, it has the meaning of 'process leading up to the endpoint' [...]. If the focus is on Phase B (between the initial point and endpoint of an action), it is a typical progressive (i.e. action in progress). If Phase $\mathrm{C}$ is focused on, it denotes a resultative state." (Shirai, 1998b, p. 671)

An English verb like understand cannot focus on any phase in the diagram above. However Japanese stative verbs render grammatical sentences when they focus on the last two phases. We will return later to the reasons responsible for this. While states present a different behaviour in the case of the progressive test, they behave in the same way as English verbs when we construct sentences based on the remaining stative-non-stative tests ${ }^{8}$. This can be seen in the examples sentences below.

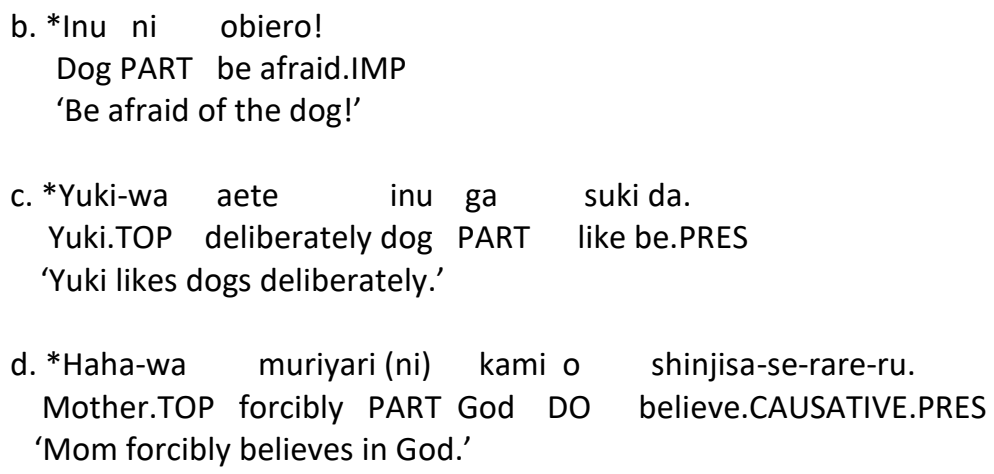

Activities also behave in the same way as their English counterparts, being compatible with all four of the preliminary tests.

9. a. Miki-san wa hanashi-te iru.

Miki-suf. TOP speak.PROG.PRES

'Mrs. Miki is talking.'

b. Hanase!

Speak.IMP

'Speak!'

c. Ken-wa aete kaigichū ni sumātofon de gēmu wo yatte-ita.

Ken-TOP deliberately during meetings PART smartphone INSTR play.IMPERF.PAST

\footnotetext{
${ }^{7}$ The compatibility with the imperfective.

${ }^{8}$ (ii) whether they can appear in imperative sentences or not, (iii) whether or not they can be modified by deliberately/carefully etc. and (iv) their compatibility with force or persuade.
} 
'Ken deliberately played on her smartphone during the meeting.'

d. Kunimitsu-kun-wa (muriyari ni) odora-se-rareta.

Kunimitsu.suf.TOP (forcibly PART) dance.CAUSATIVE.PASSIVE

Kunimitsu was forced to dance.

The sentences in (11) below, constructed on accomplishments, are also compatible with the tests Dowty which has proposed.

10. a. Kagome-san-wa pea o tabe-te iru.

Kagome.suf.TOP pear DO eat.PROG.PRES

'Ms. Kagome is eating a pear.'

b. Ima sugu ano himitsu o oshiete!

Now right away that secret DO tell.IMP

'Tell me the secret this instant!'

c. Yōko-wa aete sono hon o kattan janai no?

Yōko.Top deliberately that book DO buy.PAST right PART

'Didn't Yōko buy that book on purpose?'

d. Tanaka-kun-wa kurasumēto no mae de ano retā o yoma-se-rareta.

Tanaka.suf.TOP classmate GEN front PART that letter DO sdaread.CAUS.PASSIVE

Tanaka was forced to read that letter in front of his classmates.

Usually, in the -te iru/itta forms, the event denoted by the verb receives a present or past continuous interpretation. However, (Uesaka, 1996, p. 17) points out that accomplishments can also receive a second interpretation, that of perfect of result. We will return to this later in the paper, where we will also discuss why Japanese states appear in imperfective morphology.

Achievements are the only class of verbs that cannot be modified by -te ir ${ }^{9}$. They cannot appear in this form as their internal structure is represented as [ BECOME [ $\mathrm{x}\langle\mathrm{STATE}>$ ] ] ], nor can they take agentive adverbs like deliberately, or force/persuade. Lastly, they are odd in imperative sentences, and in (12b), the verb can only be read as a cheer uttered during a race, and not as an actual order.

11. a. *Haha-wa kuruma no kagi o mitsuke-te iru (tokoro da). Mother.TOP car GEN keys DO find.PROG.PRES (at the very moment).

'Mom is finding the car keys.

b. ?Rēsu ni kate!

Race PART win.IMP

'Win the race!'

c. *Kanja-san-wa aete shinda.

Patient.suf.TOP deliberately die.PAST

'The patient deliberately died.'

d. *Seito-wa muriyari (ni) tesuto no machigai o kizuka-se-rareta.

Student.TOP forcibly test GEN mistake DO notice.CAUSATIVE.PASSIVE

'The student was forced to spot the mistake in his test.'

Taking into consideration what we discussed above, it follows that the stative vs. non-stative tests are not sufficient to explain the differences that set one verb class apart from another. As we have seen in the case of English verbs, activities and

${ }^{9}$ When these verbs do occur accompanied by -te iru, they receive another interpretation which we will talk more about later. 
accomplishments pass all the tests. Japanese achievements fail all of the tests, and states fail three of them. We do not count here the case of Japanese stative verbs used in the progressive.

\subsection{Telic-Atelic Tests (Japanese)}

In the meantime, we will see what behaviour the Vendlerian verb classes have with a telic or atelic interpretation. To do so, we will once more rely on the tests that MacDonald (2008) proposes, and we will see if they provide us with different results than it was the case with English.

Let us start with the in/for time adverbial test, translated as de, respectively kan in Japanese.

12. a. Chichi-wa haha o sannen kan/*de aishita.

Father.suf.TOP mother DO 3 years for/in love.PAST

'Dad loved mom for/*in three years.'

b. Maria-wa ichiji kan/*de odotta.

Maria.TOP one hour for/in dance.PAST

'Maria dances for/*in one hour.'

c. Akacha-wa sanpun de/*kan momo o tabeta.

Baby-TOP three minute in/for peach DO eat.PAST

'The baby ate the peach in three minutes.'

d. Haha-wa sanjūbyō de/*kan kuruma no kagi o mitsuketa.

Sister.TOP thirty seconds in/for car GEN keys DO find.PAST

'Mom found the car keys in thirty seconds.'

Japanese statives take a time adverbial compatible with the atelic interpretation. The same is true for activities, which just like states, lack an endpoint. However according to Verkyul (1989, p. 50), English activities could be coerced to receive another interpretation. This is not the case with Japanese activities, which, when used with de, cannot be read as 'a certain amount of time elapsed before the event described by the verb started'. To convey this particular interpretation, we need to use other lexical items which are not needed in English. However, this interpretation is available for accomplishments, and we believe that the reason for this has to do with the complex nature of this verb class. Achievements, in turn, behave just like their English counterpart, and accept only the reading which tells us that a certain period of time elapsed before the event of finding the key actually occurred.

The third test is the It took $x$ time test, whose meaning is conveyed in Japanese in the following way: one would have to add the verb kakaru ('to take time') after the main verb, and to also add a combination of two particles (no $+n i)^{10}$ to signal the idea of in order for something to happen.

13. a. *Shain-ga byōki ni naru no ni yokka-kan mo kakatta. Emplyee.TOP sickness PART to become in order to four days as much as take.PAST 'It took the employee three days to become sick.'

b. Hanin-wa hanasu no ni nijikan mo kakatta.

Criminal.TOP speak.PRES in order to two hours as much as take.PAST

'It took the criminal as much as two hours to talk.'

c. Otō-san-wa sono hanashi o kataru no ni sanpun mo kakatta.

Dad.suf.TOP that story DO tell.PRES in order to three minutes as much as take.PAST

'It took dad three minutes to tell that song.'

10 There is another structure which can be used to convey this meaning, and that is verb + made ni which roughly translates as $x$ time passed before y happed. However, we will not analyse it in the present paper, as no significant differences in usage arise between the two structures. 

d. ?Ane-wa
hinto o mitsukeru no ni
sanjuppun mo
kakatta.
Big sister.TOP hint DO find.PRES in order to thirty minutes as much as take.PAST
'It took my older sister thirty minutes to find the hint.'

From the sentences above we see that states fail receive an end-time interpretation, while other verbs do so. Moreover, verbs like the one in (14d) are also incompatible with either the start-time, or the end-time interpretations due to their punctual nature. As MacDonald (2008) points out, activities are incompatible with an end-time interpretation, and this holds true for Japanese activities as well. However, accomplishments are compatible with both readings.

Almost is translated into Japanese using the construction mo sukoshi de which then combines with the present form of the conjugated verb followed by tokoro datta/deshita. What comes after the verb shows that the action expressed by the verb was just about to happen, but that in the end, it did not. From the sentences below, we see that the verb classes compatible with this construction are the same as in the case of English.

14. a. *Chichi-wa mō sukoshi de haha o aisuru tokoro datta.

Father.TOP almost mother DO love.PRES was about to

'Dad almost loved mom.'

b. Mina-wa mōsukoshi de ike de oyogu tokoro datta.

Mina.TOP almost pond.PART swim.PRES was about to

'Mina almost swam in the pond.'

c. Musuko-wa mō sukoshi de o-sara o arau tokoro datta. Son.TOP almost dishes DO wash.PRES was about to

'My son almost did the dishes.'

d. Kegashita inu-wa mō sukoshi de shinu tokoro datta. Injured dogTOP almost die.PRES was about to 'The injured dog almost died.'

Due to their nature, when states are combined with mō sukoshi de + verb + tokoro datta, they cannot be read as having a counterfactual meaning. Because of their [-telic] internal feature, the incompletive interpretation cannot transpire either, just like it is the case with English statives. Activity verbs are compatible with this construction and the only interpretation they receive is that the particular action expressed by the verb did not take place. Thus, only the counterfactual interpretation is available for them. Accomplishments can also elicit a counterfactual interpretation, like in (15c), but they can also be read as an incompletive event, where some of the dishes were washed, and some were left dirty. Lastly, achievements can only be used to signal counterfactual situations.

The last telic-atelic test is the complement of stop/finish test. In the case of stop, the verb that is used is yameru which means 'to stop, cease or discontinue' an activity. To express that something has reached its end, one can use the following two verbs: owaru, or shimau. For clarity purposes, we will first discuss the verb stop, and afterwards we will talk about finish.

15. a. Kagura-san-wa Okita-san no hanashio shinjiru no o yameta.

Kagura.suf.TOP Okita.suf GEN story DO believe.PRES NominalisingPART stop.PAST

'Kagura stopped beliving Okita's story.'

b. Maria-chan-wa hoka no hito to sukēto suru no o yameta.

Maria.suf.TOP other GEN people with skate.PRES NominalisingPART stop.PAST

'Maria stopped skating together with other people.'

c. Kare-wa ano e o egaku no o yameta.

He.TOP that picture DO paint.PRES NominalisingPART stop.PAST

'He stopped painting that painting.' 


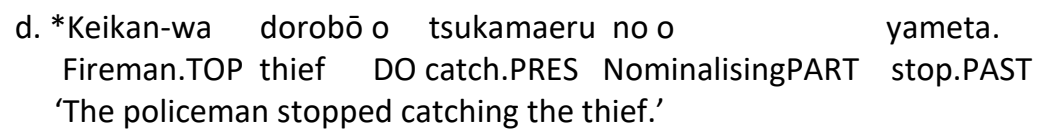

The first sentence is grammatical as the complement of stop, and so are the sentences in (16b) and (16c). States and activities, can appear with yameru because of their atelic nature which presupposes no arbitrary endpoint. (Farkas, 2017, $\mathrm{p}$. 171) explains that this is possible because after a state or activity starts, then it is true that they were performed, be it even for a short period of time. Because accomplishments share a part of their internal structure with activities, they can, of course, be stopped. Their telic nature also plays a part in this. It is not surprising to see that achievements are not compatible with stop, even though they are telic events. Achievements are instantaneous events and they cannot be stopped once they start, provided that we do not use them with iterative meaning.

Let us now see which verbs can appear as the complement of owaru or shimau. For this, we will reinterpret the sentenced above as (17a-d). Syntactically speaking, the verbs present a different behaviour, in the sense that they are immediately attached to the main verb.

16. a. *Kagura-san-wa Okita-san no hanashi o shinji-owatta/shinjite-shimatta.

Kagura.suf.TOP Okita.suf GEN story DO believe.finish.PAST

'Kagura finished believing Okita's story.'

b. *Maria-chan-wa hoka no hito to sukēto shite-owatta/sukēto shite-shimatta.

Maria.suf.TOP other GEN peolple with skate.finish.PAST

'Maria finished skating together with other people.'

c. Kare-wa ano e o egakite-owatta/yonde-shimatta.

He.TOP that painting DO paint.finish.PAST

'He finished painting that painting.'

d. *Keikan-wa dorobōo tsukamae-owatta/tsukanmaete-shimatta.

Policeman.TOP girl DO catch.finish.PAST

'The policeman finished catching thief.'

But for sentence (17c), all the other examples are ungrammatical when they are used as the complement of finish. With states and activities, this happens because of their atelic nature which does not allow them to ever be finished, although they can always be stopped. Despite their telic nature, achievements cannot be finished either, as they are instantaneous events. Accomplishments, however, are compatible with both owaru and shimau. This is because they are telic events, and also because they have duration.

Thus, we can conclude that Japanese verbs do not differ from English verbs as much as one would think. There are, however, some differences: the progressive morphology that states receive, and the state-result reading which is available for achievements when they are conjugated in the -te iru form. The purpose of the following section will be to explore these differences and the consequences that they bring about.

\subsection{Syntactic representations}

Let us return to the topic of -te iru and see why it can be combined with both states, and achievements. Travis argues that aspect is not only a semantic concept, but that it can be accounted for in syntactic terms, as Aspect seems to be a "functional category (Aspect) within the layered VP (VP)" (Travis, 2010, p. 4). She also introduces the notion of an Event Phrase (EP) which "marks the edge of the event" (Travis, 2010, p. 4). This EP is the subevent that the verb presupposes. Uesaka (1996, p. 80) simplifies Travis's view of a syntactic tree as represented below: 


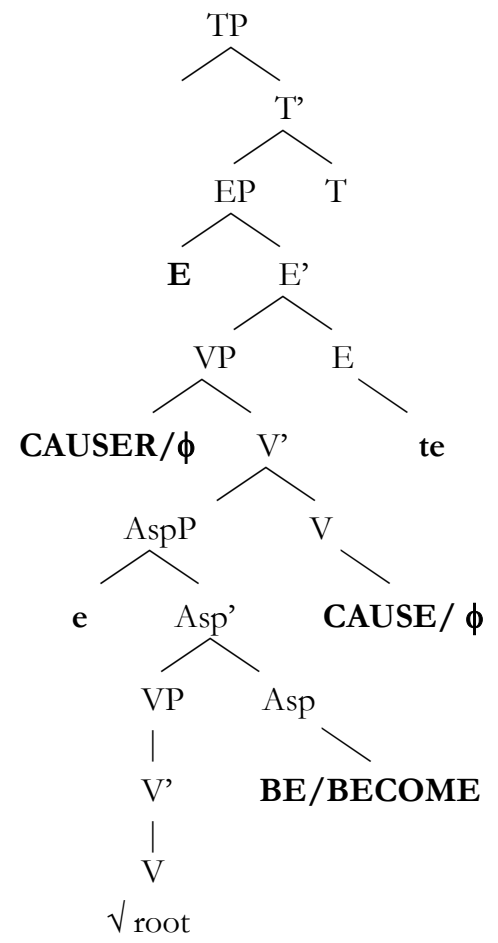

Now, let us return to achievement verbs. In Japanese, verbs were first classified by Kindaichi (1950), which used the term instantaneous verbs to refer to achievements. This is not surprising, if we remember that achievements are punctual verbs in Vendler's terms as well. Moreover, as we have already seen, they can function with imperfective morphology. However, we must ask ourselves why it is that they have this behaviour, as the English data shows they should not. Here, Smith (1991) offers an explanation, and she argues that the imperfective can actually receive two interpretations: a continuous interpretation, and a resultative one. "The resultative is an imperfective that focuses a resultant interval of a change of state" Smith (1991, p. 131). If we agree that Japanese achievements are actually used with imperfective morphology to signal a state-result reading, then we can go on to analyse achievements from this point of view. This interpretation is also closely related to the BECOME semantic operator that Rappaport Hovav and Levin (1998) have proposed. A verb which takes this operator must be telic, and because telicity means having an endpoint, it makes sense that this endpoint is linked to a result. Let us see how a syntactic tree built on an achievement would look like. We take the following sentence as an example:

17. O-cha-ga kobore-te iru.

Pref.Tea.NOM spill.SR.PRES

'The tea has spilt (and it is still on the tabletop/floor etc.).' 


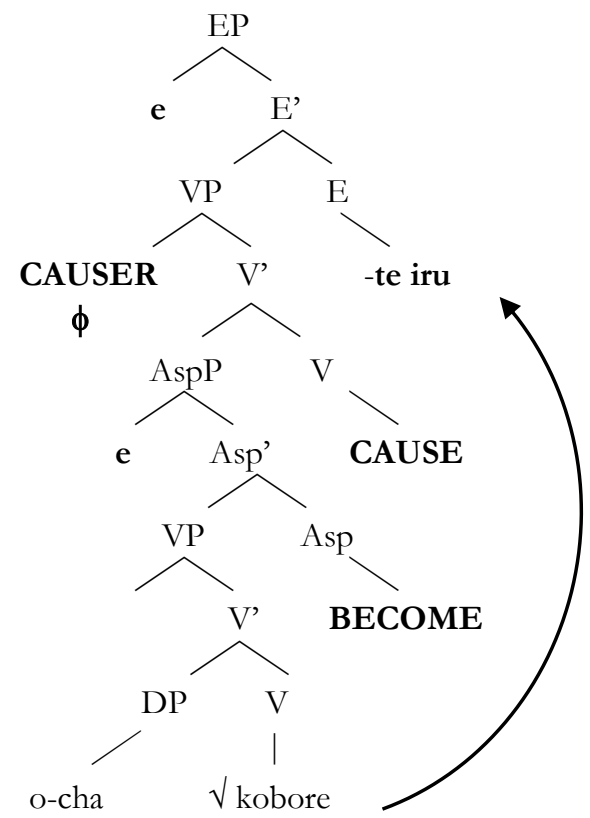

Moreover, as accomplishments are telic events, which have BECOME in their semantic representation, one would not be wrong to wonder whether these verbs can be read as having a state-result interpretation. This can be done with accomplishments as well, however, there is nothing to signal a certain reading if we take sentences out from context. Thus, in the absence of other items that would point us in the right direction, a sentence like the one below could be read either way.

18. Shizuo-kun-wa momo o tabe-te iru.

Shizuo.suf.TOP momo DO eat.SR.PRES/PROG.PRES

'Shizuo has eaten a/the peach (and there is no piece left of it).' or

'Shizuo is eating a/the peach.'

If we chose to add an adverb like mō (already) before tabe-te iru, then the the State-Result interpretation would be more prominent, although we cannot disregard a continuous reading either. Thus, the need for context becomes crucial when accounting for the right interpretation that accomplishments receive in certain sentences. We say certain sentences because in a number of cases, a state-result reading is not compatible with accomplishments. Such a sentence would be one in which the adverb ima 'now, at the moment' is present.

After having explained why achievements can appear with imperfective morphology, we must turn our attention to Japanese stative verbs. Here, one mention must be made: for clarity purposes, we chose to refer to verbs like ai suru 'to love', wakaru 'to understand', and similar verbs using the term stative. However, Kindaichi (1950) classifies these verbs under a Fourth Verbal Category, and differentiates them from states which only amount to a small number in Japanese. Such verbs would be $i u^{11} / a r u^{12}$ 'to be', niru 'to resemble', or dekiru, the English modal 'can.' These verbs cannot form grammatical sentences when combined with -te iru, but the other verbs which correspond to states in English can do this. Moreover, Ogihara (1998, p. 15) states that these verbs "must be used in the -te iru form in simple sentences."

This aspect is also reflected in the particles that the verbs collocate with in everyday sentences. Kindaichi's states are accompanied by ga, to signal that an Experiencer theta-role is assigned by the verb, while verbs like love or believe are accompanied by the topic marker wa.

\footnotetext{
${ }^{11}$ For animate entities.

12 For inanimate entities.
} 
19. Kurista-wa roshiaro ga dekiru.

Maria.TOP Russian NOM can

'Christa understands/knows Russian.'

20. Kimiko-wa ano hito o hontō ni aishi-te iru ne.

Kimiko.TOP that man DO really love.PROG.PRES PART

'Kimiko really loves that man.'

However, Uesaka (1996) chooses to refer to these verbs as not actually being in the progressive, but as being a sub-set of the state-result interpretation that was characteristic of achievements, and accomplishments. A syntactic tree built on a verb from the Fourth Verbal Category would be the following:

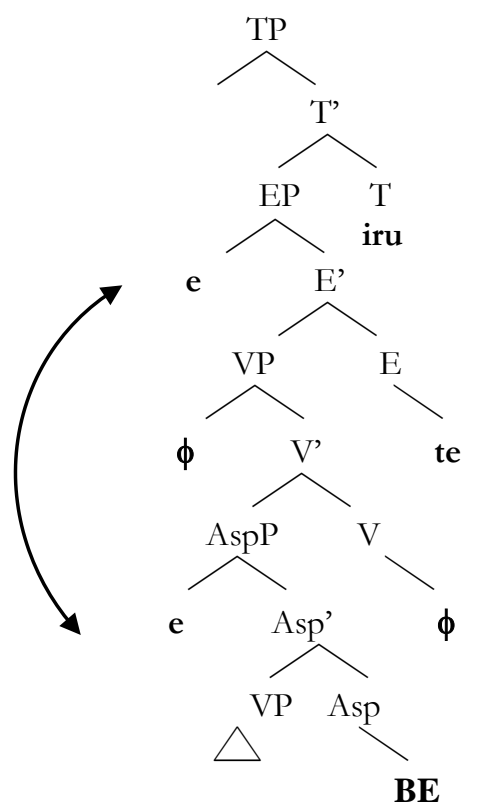

See how this differs from the syntactic tree of a Japanese stative verb, which does not have a CAUSE semantic operator because states come about without a causing subevent. As there is no EP in the representation of stative verbs, then it follows that there can be no Asp counterpart either. As Asp is directly linked to te, it makes sense that this morpheme cannot be found under the E node. Moreover, states do not have CAUSE or BECOME in their semantic representation, the only remaining semantic operator is $\mathbf{B E}$.

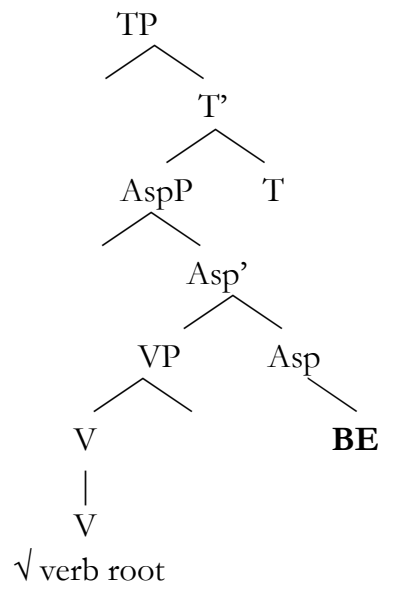


We have mentioned before that Shirai (1998b) draws a time axis to represent the three phases that the imperfective is associated with. If the progressive was correlated with Phase B, then it follows that verbs in the Fourth Verbal Category can only be correlated to Phase $\mathrm{C}$, which signals the state-result reading. The reason why these verbs cannot focus on Phase $\mathrm{A}$ has to do with the fact that they lack a causing subevent. In the case of stative verbs like dekiru (which take only one semantic operator), even though AspP is projected in the tree, the focus cannot be on any of the three phases, hence why such verbs do not appear with -te iru. It is, however, important to mention that even though English and Japanese verbs like love, hate, believe share the same internal features, only Japanese verbs can work with imperfective morphology, while English verbs cannot do this unless they have their meaning coerced. This appears to be a characteristic that sets these verbs apart in the two languages under analysis.

\section{Conclusion}

The present paper has explored Inner Aspect is English and Japanese so as to account for the two interpretations that the imperfective has been said to receive. Accounting for the reasons which bring about the two readings is imperative is order to explain why a certain interpretation is available in the case of one class of verbs, and not available for another one. Although the two languages under analysis display similar behaviours as far as Inner Aspect is concerned, the Vendlerian classification of verbs is not enough to account for a number of Japanese verbs, which appear to break the English pattern. What is responsible for this is the state-result interpretation which gives the Japanese -te iru morpheme cluster its ability to express two different interpretations, without raising confusion between the two readings. We argue that the state-result interpretation can be found in English as well, and that English achievements used with -ing can actually be grammatical if we read them as focusing Shirai's (1998b) Phase A. These ideas, along with the issue of the Japanese Fourth Verbal Category can be used as stepping stones for further research in this field of Inner Aspect.

\section{References}

[1] Comrie, B. (1976). Aspect: an Introduction to the Study of Verbal Aspect and Related Problems. Cambridge University Press.

[2] Dowty, D. (1979). Word Meaning and the Montague Grammar. D. Reidel Publishing Company.

[3] Farkas, I. A. (2017). The Syntax and Semantics of the Verb. Casa Cărții de Știință.

[4] Kindaichi, H. (1950). Kokugo dōshi no ichibunrui [A Classification of Japanese Verbs]. Kokugo Kenkyū, 15, 48-65.

[5] MacDonald, J. E. (2008). The Syntactic Nature of Inner Aspect. A Minimalist Perspective. John Benjamins.

[6] MacDonald, J. E. (2009). Inner aspect and phases. Explorations of Phase Theory: Features and Arguments, 207-229.

[7] Malka Rappaport H. \& Levin. B. (1998). Building Verb Meanings. The Projection of Arguments. Lexical and Compositional Factors, 97-134.

[8] Mourelatos, A. (1978). Events, processes and states. Linguistics and Philosophy, 2(1), 415-434.

[9] Ogihara, T. (1999). Tense and Aspect. The Handbook of Japanese Linguistics. 326-348.

[10] Ogihara, T. (1998). The ambiguity of the - TE IRU form in Japanese. Journal of East Asian Linguistics, 7, 87-120.

[11] Okuda, Y. (1978a). Asupekuto no kenkyuu o megutte, ge [On the study of aspect, II]. Kyooiku Kokugo, 54, 14-27.

[12] Okuda, Y. (1978b). Asupekuto no kenkyuu o megutte, zyoo [On the study of aspect, I]. Kyooiku Kokugo, 53, 33-44.

[13] Ramchand, G. C. (2008). Verb Meaning and the Lexicon. Cambridge. Cambridge University Press

[14] Shirai, Y. (1993). Inherent aspect and the acquisition of tense-aspect morphology in Japanese.

[15] https://www.researchgate.net/publication/246472609_Inherent_aspect_and_acquisition_of_tenseaspect_morphology_in_Japanese

[16] Shirai, Y.(1998a). The emergence of tense-aspect morphology in Japanese: universal predisposition? First Language, 18(54), 281-309.

[17] Shirai, Y. (1998b). Where the Progressive and the Resultative Meet: Imperfective Aspect in Japanese, Chinese, Korean_and English. Studies in Language, 22, 661-692.

[18] Tenny, C. L. (2000). Aspectual Roles, Modularity, and Acquisition; with a Discussion of Contact Locatives. Lexical Specification and Insertion, 197, 379-401.

[19] Tenny, C. L. (2994). Aspectual Roles and the Syntactic-Semantics Interface. Kluwer Academic Publishers.

[20] Tenny, C. L. (1987). Grammaticalizing Aspect and Affectedness. [Doctoral dissertation, MIT Press].

[21] Travis deMena, L. (2010). Inner Aspect. The Articulation of VP. Springer.

[22] Uesaka, M. (1996). The "te-i-ru" Construction in Japanese: Interaction between Aspect and Syntax. [Master's Thesis,McGill University].

[23] Vendler, Z. (1967). Verbs and Times. The Philosophical Review, 66, 143-160.

[24] Verkuyl, H. J. (1989). Aspectual Classes and Aspectual Composition." Linguistics and Philosophy, 12, 39-94.

[25] Yori, I. (2018). A Comparative Study of the Tense-Aspect System between Japanese and English. Hitotsubashi Journal of Arts and Sciences, 59(1), 1-16. 